\title{
Assessment of Low Patient Social Support and its Associated Factors Among Hospitalized Medical Surgical Adult Inpatients in Public Hospitals, Addis Ababa, Ethiopia, 2020. Multi -Center Cross-Sectional Study
}

Shegaw Tesfa ( $\nabla$ shegawtesfa201012@gmail.com )

Wolkite University https://orcid.org/0000-0002-4534-155X

\section{Haimanot Abebe}

Wolkite University

\section{Bitew Tefera}

Wolkite University

Agere Ayinalem

Wolkite University

Baye Tsegaye

Wolkite University

Temen Fetene

Wolkite University

Betilhem Tadesse

Wolkite University

Fisha Alebel

Wolkite University

Tadesse Tsehay

Wolkite University

\section{Research}

Keywords: Iow patient social support, medical surgical adult inpatients, Addis Ababa

Posted Date: June 29th, 2021

DOl: https://doi.org/10.21203/rs.3.rs-649931/v1

License: (c) (i) This work is licensed under a Creative Commons Attribution 4.0 International License.

Read Full License 


\section{Abstract}

Introduction: Patient social support is a network or web of social relationships that each individual keeps including the closest people, such as family, close friends and other neighborhood or community individuals in the hospital as well as out of the hospitals. Patient psychosocial support influences the health status and treatment effectiveness, getting quality of care in a hospitalized medical surgical inpatient. It should be practiced in hospital setting than community setting.

Objective: To assess low patient social support and its associated factors among medical surgical adult inpatients in public hospitals, Addis Ababa, Ethiopia, 2020.

Methods: Institutional based cross sectional study was conducted with 380 study subjects from March 130,2020 . Systematic random sampling technique was used and data was collected using interviewer administered questionnaire. Trained nursing students collected data, collected data was entered into Epidata 3.1 and export to SPSS version 26 for analysis, and then binary and multiple logistic regression was performed to check the association between dependent and independent variable.

Result: In this study, low level of patient social support was $61.9 \%$, while $38.1 \%$ of them have high level of patient social support. Variables being housewives [AOR=3.41; 95\% $\mathrm{Cl}(1.145-10.153)]$, chat chewing $[A O R=2.596 ; 95 \% \mathrm{Cl}(1.072-6.288)]$, psychosocial counseling [AOR=4.149; $95 \% \mathrm{Cl}(0.075-0.771)$ and Previous history of hospitalization [AOR=1.673; $95 \% \mathrm{Cl}(1.019-2.746)$ were found to be significantly associated with low patient social support. While age, sex, ethnicity, religion, income, alcohol drink, smoking, other illegal substance use, and family history of mental health problem, having mental illness, type of case and length of hospital stay were not significantly associated.

Conclusion and recommendation: The overall level of patient social support in hospitalized patients was low and being housewives, chat chewing, psychosocial counselling, and Previous history of hospitalization were significantly associated with low level of patient social support among adult inpatients, therefore health care providers should provide special consideration to those group of patients admitted to the hospitals.

\section{Introduction}

Patient social support is a network or web of social relationships that each individual keeps, including the closest people, such as family, close friends and other neighborhood or community individuals in the hospital as well as out of the hospitals (1).

Globally patient need assessments data indicates $4.7 \%$ and $34.9 \%$ of the inpatients need medical care instrumental support and $18.6 \%$ and $33.7 \%$ also need psychosocial and emotional support from their care providers and other people of the community respectively (2). 
In western area, $45.6 \%$ of patients need the availability of support in the management and resolution of operational issues of treatment, practical activities of daily living, material and financial and more than $50.6 \%$ patients need psychosocial support regarding the availability of listening, attention, information, esteem, and companionship to satisfy (3).

Social support involves attempts to aid and reinforce someone own efforts to positively change his or her health behavior and an interactions that influence, regulation, constraints and comprises to change someone health behavior who has been unable or unwilling to make such changes $(4,5)$. Patient social support has a remarkable importance in preventing psychological instability like anxiety, stress and depression that are commonly observed in hospitalized in and out patients and $31.8 \%$ of hospitalized patients found need of psychological support (6) .

In American health care need assessment, $80 \%$ of physicians reported that they lacked confidence in their capacity to meet patient social needs and $85 \%$ of primary care providers agreed unmet social needs of their patients (7). Patient social support and assistance with daily life are important elements of the endeavor to reduce and compensate for the disadvantages that result from the diagnosis of the diseases and its therapies (8).

In Ethiopia around 58.5\% the overall need of patient support from all aspects of medical care necessity from professional health care providers and other individuals, groups, friends, neighborhood, and their relative living in the same house and in the different house (9).

Hospitalized inpatients require committed social support from different views of sides and patient support is a vital issue in coping adverse life situations in the hospitals (10). Patient social support is associated with behaviors of patient adherence to treatments and feeling of stability and psychological well-being; which seem to reduce individual susceptibility to diseases and act as protective factors of health related problem to the hospitalized patients (11).

A number of related factors like being female sex, younger age, lower educational status, single marital status, rural residence, alone living condition, substance use, and previous history of hospitalization were significantly associated with low level of patient social support. While occupation, family history of mental illness, and comorbidity has not been encountered statistically significant and some variables like having mental illness, type of case and psychosocial counseling were not statistically tested $(4,9,12-15)$

Patient supporter group was an important tool in the process of strengthening patient resources supply, developing relationships, promoting autonomy, improving self-image and self-esteem, acting in the fight against social isolation of hospitalized inpatients (16).

Although the need and importance of patient social support should have been raised, as far as on my search of studies on level of patient social support among medical surgical adult inpatients in Ethiopian have been scarce information, and not done in public hospitals, Ethiopia. Few studies done abroad this country also miss important variables, not statistically significant and were not specific to medical 
surgical adult inpatients. Therefore, this study were fill such gaps and provide information on level of patient social support and its associated factors among medical surgical adult inpatients.

\section{Study Objectives}

General objective - To assess low patient social support and its associated factors among medical surgical adult inpatients in public hospitals, Addis Ababa, Ethiopia, 2020.

Specific objectives - To determine low patient social support and identify factors associated with low patient social support among medical surgical adult inpatients.

\section{Methods And Materials}

\section{Study area and period}

Addis Ababa, capital city of the Federal Democratic Republic of Ethiopia, located at the center of the country that had 10 sub-cities and 116 Woredas with a total population of around 3.4 million according to Ethiopian population projection for all regions in Wereda level from 2014-2017 (17). Its area was estimated to be $530 \mathrm{Km}^{2}$ with altitude ranging from 2200 to 3000 meter above sea level, average temperature of $22.8^{\circ} \mathrm{C}$ and average rainfall of $1,180.4 \mathrm{~mm}^{3}$. Addis Ababa had 53 hospitals of which 13 were public and 40 were private. Setting of study were in four randomly selected hospitals from Addis Ababa public hospitals, Ethiopia; which were TASH had 374 adult inpatients, St.paulos hospital had 237 adult inpatients, Yikatit 12 hospitals had 139 adult inpatients and Zewuditu hospitals had 72 adult inpatients at a time. The study was conduct from March1 to 30, 2020.

Study design-An institution based cross - sectional study design was used.

Source population- All hospitalized medical surgical adult inpatients at selected public hospitals.

Study population- Randomly selected hospitalized medical surgical adult inpatients available during the study period and who fulfilled the inclusion criteria.

Inclusion criteria- All medical surgical inpatients greater than or equal to 18 years old present during data collection.

Exclusion criteria - Medical surgical adult inpatients unable to communicate with critical illnesses, physical impairment to speech, mental disability and post anesthesia were excluded.

Sample size determination-The sample size was calculated by using single population proportion formula, considering the following assumptions; prevalence of patient with high social support $33.5 \%$ which done in Harare public hospitals among medical surgical adult inpatients, $95 \%$ confidence interval and $5 \%$ margin of error (18) . 


$$
\mathrm{n}=\left(\mathrm{Z}_{\alpha / 2}\right)^{2}(\mathrm{pq}) / \mathrm{d}^{2}=\frac{(\mathbf{1 . 9 6})(\mathbf{1 . 9 6})(\mathbf{0 . 3 4})(\mathbf{1 - 0 . 3 4 )}}{(\mathbf{0 . 0 5})(\mathbf{0 . 0 5})}=345 \text { with } 10 \% \text { non-response rate the sample size were }
$$

380.

\section{Operational definition}

Low patient social support: Based on the social support questionnaire (SSQ-6) who scored lower than the mean.

Substance use: Patients used specific addictive and illegal substance in the last 1 year.

\section{Sampling procedure}

Four hospitals selected using of simple random sampling lottery method, which were TASH, St.paulos hospital, Yikatit hospital and Zewuditu hospital and a total of 380 study subjects were selected from 822 reference population using systematic random sampling every $\mathrm{k}=2$ interval.

\section{Study variables}

The dependent variable was low patient social support. The independent variables included sociodemographic factors (age, sex, religion, ethnicity, residence, occupation, monthly income, marital status, education status), Substance use related variables (smoking, alcohol drink, chat chewing, illegal drug use), living condition, clinical related variable (psychosocial counseling, family history of mental illness, having prior history mental illness, having mental illness, Previous history of hospitalization, type of case, comorbidity, hospital stay).

\section{Data collection tool and procedure}

Amharic version of the questionnaire was used for data collection. First, the questionnaire was prepared in English language then translated to Amharic and back to in English. Two clinical staffs as supervisor and four nursing students as data collectors with half day time training were used. Social support assessed by (SSQ-6) it included 6- items scale that assessed the number of available social support. The total score is obtained by summing all six items with a possible range of 0 to 6 and the value above the mean indicate higher levels of available social support whereas below the mean indicates lower level of available social support. The reliability coefficient for these items was 0.86 (19).

\section{Data processing and analysis}

First, the data was checked for its completeness and consistency, and then it was coded and entered in EPI data version 3.02 software. After entry, data was exported to statistical package for social science (SPSS) version 26 for analysis. Descriptive analysis using frequencies, proportions, graphs was performed to describe number and percentage of socio-demographic characteristics of the sample and other variables. Binary logistic regression analyses model was used to identify associated factors of patient social support. This was done by odds ratio and p value with 95\% confidence interval (CI). 
Explanatory variables with $p$-value $\leq 0.25$ in the bivariate logistic regression was entered into multivariate logistic regression analysis to control possible confounding. Hosmer-Lemeshow's test was found to be insignificant ( $p$-value $=0.999)$ and Omnibus tests was significant ( $P$-value $=0.001)$ which indicate the model was fitted. P-value of less than 0.05 was used to declare level of statistical significant and adjusted odd ratio (AOR) with $95 \% \mathrm{Cl}$ was estimated to identify significantly associated variables with the dependent variable, low level of patient social support. Finally, the results were presented in text, tables and graphs based on the types of data.

\section{Result}

\section{Socio-demographic characteristics of the study participants}

In this study, the data were collected from 380 respondents through face-to-face interviews with the response rate of $98.7 \%$. Among those 202 (53.9\%) were female, $82(21.9 \%)$ were in the age group of $25-$ 34 and the mean age of the participants was 40.8 years with standard deviation of \pm 15 .72. From the study participants 147 (39.2\%) were Amhara ethnicity and 241 (64.3\%) live in urban, 225 (60\%) were orthodox religion, $222(59.2 \%)$ were married, 97 (25.9\%) have primary education and $92(24.5 \%)$ were farming occupation. Majority of the respondents have low income 196 (52.3\%) (Table 1).

Table 1: Sociodemographic characteristics of study participants in public hospitals, Addis Ababa, Ethiopia, $2020(n=380)$. 


\begin{tabular}{|c|c|c|c|}
\hline Variables & Category & Frequency & Percent (\%) \\
\hline \multirow[t]{6}{*}{ Age } & 18 to 24 & 61 & 16.3 \\
\hline & 25 to 34 & 82 & 21.9 \\
\hline & 35 to 44 & 76 & 20.3 \\
\hline & 45 to 54 & 67 & 17.9 \\
\hline & 55 to 64 & 56 & 14.9 \\
\hline & 65 and more & 33 & 8.8 \\
\hline \multirow[t]{2}{*}{ Sex } & Female & 202 & 53.9 \\
\hline & Male & 173 & 46.1 \\
\hline \multirow[t]{5}{*}{ Religion } & Orthodox & 225 & 60.0 \\
\hline & Muslim & 83 & 22.1 \\
\hline & Protestant & 55 & 14.7 \\
\hline & Catholic & 8 & 2.1 \\
\hline & Others & 4 & 1.1 \\
\hline \multirow[t]{4}{*}{ Marital status } & Single & 106 & 28.3 \\
\hline & Windowed & 25 & 6.7 \\
\hline & Divorced & 22 & 5.9 \\
\hline & Married & 222 & 59.2 \\
\hline \multirow[t]{6}{*}{ Ethnicity } & Amhara & 147 & 39.2 \\
\hline & Oromo & 105 & 28.0 \\
\hline & Tigray & 31 & 8.3 \\
\hline & Gurage & 42 & 11.2 \\
\hline & Silte & 23 & 6.1 \\
\hline & Others & 27 & 7.2 \\
\hline \multirow[t]{2}{*}{ Residence } & Urban & 241 & 64.3 \\
\hline & Rural & 134 & 35.7 \\
\hline \multirow[t]{3}{*}{ Education } & Can't read and write & 79 & 21.1 \\
\hline & Can read and write & 57 & 15.2 \\
\hline & Primary & 97 & 25.9 \\
\hline
\end{tabular}




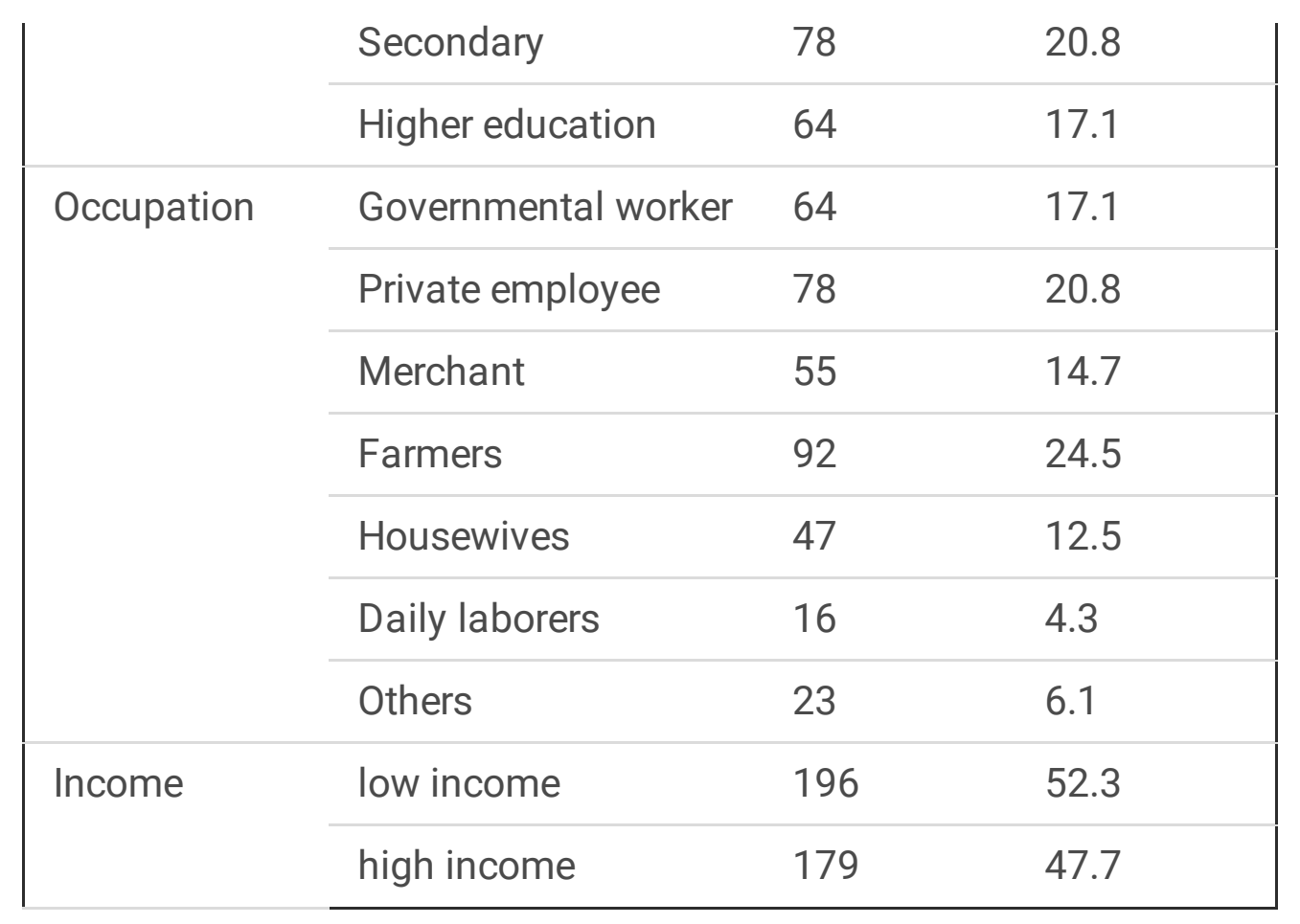

\section{Substance use related factors of patient social support}

From the study participants 46 (12.3\%) were used chat, 122 (32.5\%) used alcohol, 17 (4.5\%) used tobacco and three $(0.8 \%)$ were used other illegal substances like hashish (Table 2$)$.

Table 2: Substance used related factors of study participants in public hospitals, Addis Ababa, Ethiopia, $2020(n=380)$.

\begin{tabular}{|llll|}
\hline Variables & Category & Frequency & Percent (\%) \\
\hline Chat chewing & Yes & 46 & 12.3 \\
\cline { 2 - 4 } & No & 329 & 87.7 \\
\hline Alcohol drink & Yes & 122 & 32.5 \\
\cline { 2 - 4 } Smoking & No & 253 & 67.5 \\
\multirow{2}{*}{ Other illegal drugs used } & Yes & 3 & 4.5 \\
\cline { 2 - 4 } & No & 358 & 95.5 \\
\cline { 2 - 4 } & No & 372 & 0.8 \\
\cline { 2 - 4 } & & & 99.2 \\
\hline
\end{tabular}

\section{Living condition related factors of patient social support}

Among the study participants 311 (82.9\%) were live with their family, $55(14.7 \%)$ were live alone and nine (2.4\%) were live with others (Table 3). 
Table 3: Living condition related factors of study participants in public hospitals, Addis Ababa, Ethiopia, $2020(n=375)$.

\begin{tabular}{llll} 
Variables & Category & Frequency & Percent (\%) \\
\hline Living condition & Alone & 55 & 14.7 \\
\cline { 2 - 4 } & Family & 311 & 82.9 \\
\cline { 2 - 4 } & Others & 9 & 2.4
\end{tabular}

\section{Clinical related factors of patient social support}

Among the study participants 201 (53.6\%) were having medical case, 187 (49.9\%) had previous history of hospitalization, 144 (38.4\%) had comorbid disorder, 133 (35.5\%) were stay at the hospital for $<1$ week, 110 (29.3) stay for 1 to 2 week and 132 (35.2) stay for more than 2 weeks. From the respondents $56(14.9 \%)$ had family history of psychiatric illness, 17 (4.5\%) had gotten psychiatric counseling, $17(4.5 \%)$ had previous history of psychiatric condition and $6(1.6 \%)$ had current psychiatric condition (Table 4).

Table 4: Clinical related factors of study participants in public hospitals, Addis Ababa, Ethiopia, 2020 $(n=380)$. 


\begin{tabular}{llll} 
Variables & Category & Frequency & Percent (\%) \\
\hline Previous history of mental illness & Yes & 17 & 4.5 \\
\cline { 2 - 4 } & No & 358 & 95.5 \\
\hline Having mental illness & Yes & 6 & 1.6 \\
\cline { 2 - 4 } & No & 369 & 98.4 \\
\hline Psychosocial counseling & Yes & 17 & 4.5 \\
\cline { 2 - 4 } & No & 358 & 95.5 \\
\hline Family history of mental illness & Yes & 56 & 14.9 \\
\cline { 2 - 4 } & No & 319 & 85.1 \\
\hline Type of case & Surgical & 174 & 46.4 \\
\cline { 2 - 4 } & Medical & 201 & 53.6 \\
\hline Previous history of hospitalization & Yes & 187 & 49.9 \\
\cline { 2 - 4 } & No & 188 & 50.1 \\
\hline Having comorbidity disorder & Yes & 144 & 38.4 \\
\cline { 2 - 4 } & No & 231 & 61.6 \\
\hline Time stayed in hospital & $<1$ week & 133 & 35.5 \\
\cline { 2 - 4 } & $1-2$ week & 110 & 29.3 \\
\cline { 2 - 4 } & $>2$ week & 132 & 35.2 \\
\hline
\end{tabular}

\section{The low level of patient social support}

In this study the level of patient social support among hospitalized medical surgical inpatient in public hospitals, Addis Ababa, Ethiopia, 2020 ( $n=380)$ were 232 (61.9\%) have low level patient social support and $143(38.1 \%$ ) have high level of patient social support (figure 1).

\section{Factor associated with low level of patient social support}

Those variables with a P-value of $\leq 0.25$ in the binary logistic analysis was entered to multiple logistic analysis using enter method to identify the independent factors associated with low level of patient social support among hospitalized inpatients. In bivariate analysis the covariates: age, sex, marital status, educational status, occupation, income, chat chewing, alcohol drink, smoking, living condition, previous history of mental illness, psychosocial counseling, family history of mental illness, having mental illness, having Previous history of hospitalization, time of hospital stay and type of case were associated with low level of patient social support among adult inpatients. In multiple logistic regression 
analysis, covariates: being housewives, chat chewing, psychosocial counselling and Previous history of hospitalization were associated with low level of patient social support by $95 \%$ confidence interval.

In this study participants being housewives were statistically associated $(p=0.028)$ with low level of patient social support; being housewives was 3.4 times having low level patients social support $[A O R=3.41 ; 95 \% \mathrm{Cl}(1.145-10.153)]$ than being a governmental employ.

Regarding on substance use participants who were chewing chat were significantly associated $(\mathrm{p}=$ 0.035 ) with low level of patent social support and almost 2.6 times more likely to have low level of patient social support $[A O R=2.596 ; 95 \% \mathrm{Cl}(1.072-6.288)$ than those who were not chewing chat.

Those hospitalized adult inpatients who have psychosocial counseling were negatively associated $(p=0.016)$ with low level of patient social support meaning that adult inpatients who have psychosocial counseling were 4.2 times more likely to have high level of patient social support than inpatients who have no psychosocial counseling [AOR=4.149; $95 \% \mathrm{Cl}(0.075-0.771)]$.

Respondents who have previous history of hospitalization was positively associated $(p=0.042)$ with low level of patient social support and patients who had previous history of hospitalization were 1.7 times having low level of patient social support [AOR=1.673; 95\% Cl (1.019-2.746)] than patients have no previous history of hospitalization (Table 5).

Table 5: Binary and multiple logistic regression analysis of factors associated with low level of patient social support among hospitalized medical surgical adult inpatients in public hospitals, Addis Ababa, Ethiopia, 2020. 


\begin{tabular}{|c|c|c|c|c|c|c|}
\hline \multirow[t]{2}{*}{ Variables } & \multirow[t]{2}{*}{ Category } & \multicolumn{2}{|c|}{$\begin{array}{l}\text { Low patient } \\
\text { social support }\end{array}$} & \multirow[t]{2}{*}{$\begin{array}{l}\text { Crude Odd } \\
\text { Ratio }\end{array}$} & \multirow[t]{2}{*}{$\begin{array}{l}\text { Adjusted Odd } \\
\text { Ratio }\end{array}$} & \multirow[t]{2}{*}{$\begin{array}{l}\mathrm{P} \text { - } \\
\text { value }\end{array}$} \\
\hline & & Yes & No & & & \\
\hline \multirow[t]{6}{*}{ Age } & 18 to 24 & 37 & 24 & 1.00 & 1.00 & \\
\hline & 25 to 34 & 51 & 31 & $\begin{array}{l}1.067(0.540- \\
2.108)\end{array}$ & $0.538(0.144-2.000)$ & 0.355 \\
\hline & 35 to 44 & 42 & 34 & $\begin{array}{l}0.801(0.404- \\
1.589)\end{array}$ & $0.716(0.221-2.319)$ & 0.578 \\
\hline & 45 to 54 & 38 & 29 & $\begin{array}{l}0.850(0.420- \\
1.721)\end{array}$ & $0.360(0.117-1.103)$ & 0.074 \\
\hline & 55 to 64 & 38 & 18 & $\begin{array}{l}1.369(0.640- \\
2.930)\end{array}$ & $0.382(0.125-1.162)$ & 0.090 \\
\hline & $\begin{array}{l}65 \text { and } \\
\text { above }\end{array}$ & 26 & 7 & $\begin{array}{l}2.409(0.904- \\
6.419)\end{array}$ & $0.498(0.159-1.556)$ & 0.230 \\
\hline \multirow[t]{2}{*}{ Sex } & Male & 60 & 113 & 1.00 & 1.00 & \\
\hline & Female & 83 & 119 & $\begin{array}{l}1.314(0.863 \\
-2.000)\end{array}$ & 0.674(0.3791-.199) & 0.180 \\
\hline \multirow[t]{4}{*}{ Marital status } & Single & 57 & 49 & 1.00 & 1.00 & \\
\hline & Windowed & 17 & 8 & $\begin{array}{l}1.827(0.726- \\
4.598)\end{array}$ & $\begin{array}{l}0.8419(0.397- \\
1.782)\end{array}$ & 0.651 \\
\hline & Divorced & 13 & 9 & $\begin{array}{l}1.242(0.489- \\
3.153)\end{array}$ & $1.377(0.440-4.308)$ & 0.582 \\
\hline & Married & 145 & 77 & $\begin{array}{l}1.619(1.010- \\
2.594)\end{array}$ & $1.357(0.435-4.238)$ & 0.599 \\
\hline \multirow[t]{2}{*}{ Residence } & Urban & 137 & 104 & 1.00 & 1.00 & \\
\hline & Rural & 95 & 39 & $\begin{array}{l}1.849(1.177- \\
-2.905)\end{array}$ & $1.036(0.5421-.9820$ & 0.914 \\
\hline \multirow[t]{5}{*}{ Education } & $\begin{array}{l}\text { Can't read } \\
\text { and write }\end{array}$ & 58 & 21 & $\begin{array}{l}3.333(1.654- \\
6.719)\end{array}$ & $1.762(0.621-5.000)$ & 0.287 \\
\hline & $\begin{array}{l}\text { Can read and } \\
\text { write }\end{array}$ & 32 & 25 & $\begin{array}{l}1.545(0.753- \\
3.168)\end{array}$ & $0.959(0.348-2.638)$ & 0.935 \\
\hline & Primary & 61 & 36 & $\begin{array}{l}2.045(1.076- \\
-3.885)\end{array}$ & $1.440(0.587-3.531)$ & 0.426 \\
\hline & Secondary & 52 & 26 & $\begin{array}{l}2.414(1.222- \\
4.770)\end{array}$ & $2.127(0.881-5.134)$ & 0.093 \\
\hline & $\begin{array}{l}\text { Higher } \\
\text { education }\end{array}$ & 29 & 35 & 1.00 & 1.00 & \\
\hline
\end{tabular}


Occupation

Government

29

35

1.00

1.00

employee

\begin{tabular}{|c|c|c|c|c|c|}
\hline $\begin{array}{l}\text { Private } \\
\text { worker }\end{array}$ & 51 & 27 & $\begin{array}{l}2.280(1.157- \\
4.491)\end{array}$ & $2.036(0.891-4.653)$ & 0.092 \\
\hline Merchant & 33 & 22 & $\begin{array}{l}1.810(0.872- \\
3.757)\end{array}$ & $1.756(0.676-4.563)$ & 0.248 \\
\hline Farmers & 68 & 24 & $\begin{array}{l}3.420(1.737- \\
6.732)\end{array}$ & $2.396(0.871-6.597)$ & 0.091 \\
\hline Housewives & 35 & 12 & $\begin{array}{l}3.520(1.551- \\
7.991)\end{array}$ & $3.41(1.145-10.153)$ & 0.028 \\
\hline $\begin{array}{l}\text { Daily } \\
\text { laborers }\end{array}$ & 3 & 13 & $\begin{array}{l}0.279(0.072- \\
1.073)\end{array}$ & $0.343(0.066-1.776)$ & 0.202 \\
\hline Others & 13 & 10 & $\begin{array}{l}1.569(0.601- \\
4.098)\end{array}$ & $1.901(0.532-6.789)$ & 0.323 \\
\hline
\end{tabular}

Monthly income

Low

$130 \quad 66$

1.487(0.978

2.260)

0.998

High

$102 \quad 77$

1.00

1.00

Chat chewing

Yes

212

117
2.356(1.261-
4.401)

$2.596(1.072-6.288) \quad 0.035$

No

20

26

1.00

1.00

Alcohol drink

Yes

$169 \quad 84$

1.884(1.2122.929)

$1.690(0.978-2.920) \quad 0.060$

No

63

59

1.00

Smoking

Yes

$226 \quad 132$

3.139(1.1358.684)

$0.882(0.222-3.508) \quad 0.858$

No

6

11

1.00

1.00

Living condition

Live alone

18

37

0.243(0.0541.086)

$0.215(0.039-1.176) \quad 0.076$

With family $208 \quad 103$

1.010(0.2484.119)

$0.785(0.159-3.886) \quad 0.767$

Others

6

3

1.00

1.00

Psychosocial
counseling

Yes

$132 \quad 226$

0.319(0.1150.881 )

4.149(0.075-0.771)

0.016

counseling

No

11

6

1.00

1.00

Previous history of Yes

hospitalization

\begin{tabular}{lllll}
82 & 106 & $\begin{array}{l}1.598(1.050- \\
2.432)\end{array}$ & $1.673(1.019-2.746)$ & 0.042 \\
\hline 61 & 126 & 1.00 & 1.00 &
\end{tabular}




\begin{tabular}{|c|c|c|c|c|c|c|}
\hline \multirow[t]{2}{*}{ Type of case } & Surgical & 99 & 75 & 1.00 & 1.00 & \\
\hline & Medical & 133 & 68 & $\begin{array}{l}1.482(0.975- \\
2.252)\end{array}$ & $1.412(0.857-2.327)$ & 0.176 \\
\hline \multirow{3}{*}{$\begin{array}{l}\text { Hospital stay in } \\
\text { weeks }\end{array}$} & $<1$ week & 78 & 55 & 1.00 & 1.00 & \\
\hline & 1-2 weeks & 73 & 37 & $\begin{array}{l}1.391(0.823- \\
2.352)\end{array}$ & $1.205(0.039-2.233)$ & 0.553 \\
\hline & $>2$ weeks & 81 & 51 & $\begin{array}{l}1.120(0.685- \\
1.831)\end{array}$ & $0.977(0.159-1.734)$ & 0.938 \\
\hline
\end{tabular}

\section{Discussion}

\section{Low levels of patient social support}

In this study, $61.9 \%$ of patients have low level of patient social support; which is in line within $(95 \% \mathrm{Cl}, 57$ $\%-67 \%)$. This finding was relatively comparable with study reported from Finland among emergency inpatients social support, and Amanuel mental health hospital, Ethiopia in hospitalized inpatient care givers social support were $64.2 \%$, and $66.5 \%$ respectively $(9,20)$.

In this study, the prevalence of low patient social support was relatively lower than the studies conducted in Greece, and Gahanna patient social support level were $71 \%$, and $83.7 \%$ respectively $(13,21)$. This variation may be resulted from community health as a global prioritizing concern, change in improving community health policy, service development of community health care and patients' life style modification and change in safety relatively increase patient social support, and even change in methodological system might be the possible cause of the difference.

The prevalence of this study, low patient social support was relatively higher than the studies reported from USA in San Francisco general hospital, Germen hospitals in cancer patient social support and Brazil were $31.1 \%, 30.7 \%$ and $19.6 \%$ respectively $(22-24)$. This variation might be resulted from high land and scattered geographical nature, sociocultural diversity of people, sociodemographic variety, environmental factors and poor social communication network trend in our population may decrease the level of patient social support.

\section{Factors associated with hospitalized patient social support}

In this study, adult inpatients being housewives occupational status have been 3.4 times statistically associated with low level of patient social support than being governmental employee, which have high level of social support in the hospital. This result was similar to the study conducted in Nigeria among HIV patients (25). This might be resulted from peoples living in Ethiopia have the cultural habit of housewives are considered as a homemakers with in the home compound and have not allowed to work on field work areas and also they are living a separately from social relationship, communication and integration to others, which may drop their social support relationships. However in this community the 
population gives high respect, dignity to government-employed individual, and government employers have excess in number of customers contact daily at a work place some employees may also work on customer satisfaction, community mobilization and social affaire areas, which enhance social support and relationship.

Patients who are chewing chat were statistically associated and 2.6 times more likely having low level of patient social support than those who are not chewing chat. This study was consistence to the study conducted in Nigeria (25). The reason might be resulted from people with substance abuse are domestically violated, isolated and neglecting and poor social relationship from the community.

Participants who have psychosocial counseling were negatively associated with low patient social support meaning that positively associated with high patient social support. Having psychosocial counseling had been 4.2 times less likely to have low level patient social support in the hospital than those have no psychosocial counseling. There is no similar study show that this variable statistically significant. This might be resulted from they get psychosocial advice from psychological and psychiatric counselors and advocators may enhance the level of social support.

On this study, respondents with previous history of hospitalization have 1.7 times more likely to have low level of patient social support than those have no previous history hospitalization. This result is similar to a study conducted in USA (12). This outcome might be resulted from the community perception; which are patients who have repeatedly hospitalized are considered as source of infections, high transmission rate to other, acute diseases, discriminated and away from social community might be the possible cause of having low-level patient social support.

\section{Strength}

- Standardized and valid questionnaires was used in this study.

- Many different variables were assessed and new variables were added to assess.

\section{Limitation}

- Medical surgical hospitalized adult inpatients in private hospitals were not included.

- The study was cross-sectional study and did not describe cause- effect relationship.

\section{Conclusion}

The level of patient social support among hospitalized adult inpatients in Addis Ababa public hospitals were low. Being housewives, chewing chat, psychosocial counselling and patients having previous history of hospitalization were statistically associated with low level of patient social support among hospitalized medical surgical adult inpatients.

\section{Abbreviations And Acronyms}


AAU: Addis Ababa University; AOR: Adjusted Odd Ratio; Cl: Confidence Interval; COR: Crude Odd Ratio; SPSS: Statistical Package for Social Sciences; SSQ: Social Support Questionnaire; TASH: Tikure Anbessa Specialized Hospital

\section{Declarations}

Acknowledgements: First we would like to say thank to Addis Ababa University for providing ethical clearance to conduct this research. We want to thank also data collectors for their cooperation to do this research. Finally, we would like to thank all study participants for their consent to provide baseline data

Contributors: ST: draft proposal, lead data collection and analysis process wrote final thesis and prepare manuscript, HA and BT: Revised and edit proposal \& thesis, support data collection and analysis, revised thesis manuscript, AA, BT, BT, TT, FA and TF: Reviewed different literatures, revised proposal, thesis manuscript and participated in data collection. All authors revised, consent and approved the final version of the thesis and manuscript.

Consent for publication: Not applicable

Competing interests: Authors declared no any conflicts of interest with respect to the research, authorship or publication of this article.

Funding: Authors no received any financial support for conducting and publication.

Ethical considerations: Ethical approval was obtained from college of health sciences Ethics Review Committee, Addis Ababa University, and permission was obtained from each setting hospital. Informed consent was obtained from each participant to conduct the study. All information communicated with the participants, was kept private and confidential. Coding and aggregate reporting was used to eliminate respondents' identification, ensure anonymity and confidentiality, and the data were used only for the research purpose. In addition to this, we can confirm that all methods were performed in accordance with the relevant guidelines and regulations of the university.

\section{References}

1. Renata T, Brito P De, Cristina S, Pavarini I. elderly persons with cognitive alterations 1. 2012;20(4).

2. Poliana T, Moraes R, Aparecida R, Dantas S. evaluation of social support among surgical cardiac. 2007;15(2):323-9.

3. Maria E, Seidl F, Tróccoli BT. Desenvolvimento de Escala para Avaliação do Suporte Social em HIV / aids Development of a Scale for the Social Support Evaluation in HIV / Aids. 2006;22:317-26.

4. Ungar N, Wiskemann J, Weißmann M, Knoll A, Steindorf K, Sieverding M. Social support and social control in the context of cancer patients ' exercise: A pilot study. 2016; 
5. Helgeson VS, Novak SA, Lepore SJ, Eton DT. Spouse social control efforts: Relations to health behavior and well-being among men with prostate cancer. 21(1):53-68.

6. Edib Z, Kumarasamy V, binti Abdullah N, Rizal AM, Al-Dubai SAR. Most prevalent unmet supportive care needs and quality of life of breast cancer patients in a tertiary hospital in Malaysia. Health Qual Life Outcomes [Internet]. 2016;14(1):1-10. Available from: http://dx.doi.org/10.1186/s12955-0160428-4

7. Shier BG, Ginsburg M, Howell J, Volland P, Golden R. Strong Social Support Services, Such As Transportation And Help For Caregivers, Can Lead To Lower Health Care Use And Costs. 2013;3(3):544-51.

8. Diddana TZ. Factors associated with dietary practice and nutritional status of pregnant women in Dessie town, northeastern Ethiopia: A community-based cross-sectional study. BMC Pregnancy Childbirth. 2019;19(1):1-10.

9. Ababa A. Schizophrenia Attending Out Patient Department At Amanuel Mental Level of Perceived Social Support and Associated Factors Among People With Schizophrenia Attending Out Patient Department At Amanuel Mental Specialized. 2019;(March).

10. Cohen S. Social Relationships and Health. June, 2014.

11. Lopes CS. Medidas de rede e apoio social no Estudo Pró-Saúde: pré-testes e estudo piloto Social network and social support measures fro $\mathrm{m}$ the P r ó - $\mathrm{S}$ a ú d e Study: pre-tests and pilot study. 2001;17(4):887-96.

12. Chan B, Goldman LE, Sarkar U, Guzman D, Critchfield J, Saha S, et al. High perceived social support and hospital readmissions in an older multi-ethnic , limited English proficiency , safety-net population. 2019;6:1-9.

13. Theodoritsi A, Aravantinou M, Gravani V, Vasilopoulou C, Theofilou P, Poli- M. Factors Associated with the Social Support of Hemodialysis Patients. 2016;45(10):1261-9.

14. Mari J, Fortes S. Social Support patterns in Primary Health Care: differences between having physical diseases or mental disorders Social Support patterns in Primary Health Care: differences between having physical diseases or mental disorders. 2018;(July).

15. Folasire OF, Akinyemi O, Owoaje E. Perceived Social Support among HIV Positive and HIV Negative People in Ibadan, Nigeria. January, 2014.

16. Care THE, Chronic FOR, In C, Health P. THE CARE FOR CHRONIC CONDITIONS IN PRIMARY HEALTH CARE. 2018;31:1-3.

17. Ababa A. Federal Democratic Republic of Ethiopia Central Statistical Agency Population Projection of Ethiopia for All Regions At Wereda Level from 2014 - 2017. August, 2017.

18. Tilahun H, Awoke N, Geda B, Mesfin F. Depression and Associated Factors among Adult Inpatients at Public Hospitals of Harari Regional State, Eastern Ethiopia. Psychiatry J. 2018;2018:1-6.

19. Agazhu HW, Giru BW, Wurjine TH. Prevalence and Associated Factors of Depression among HIV/AIDS Patients Attending Anti-Retroviral Therapy Clinics at Gurage Zone Selected Government 
Hospitals, Southwest, South nations, Nationalities and Peoples' Region, Ethiopia, 2018. 2018;9(12):971-83.

20. Demidenko J, Routasalo P, Helminen M, Astedt-kurki P. Social support received by the family of older patients in emergency department: A cross-sectional study. 2017;(December).

21. Abrefa-gyan T. Social support and support groups among people with HIV / AIDS in Ghana Social Support and Support Groups Among People With HIV / AIDS in Ghana. December, 2015.

22. Dinicola G, Julian L, Gregorich SE, Blanc PD, Katz PP. NIH Public Access. 2014;74(2):110-5.

23. Ungar N, Wiskemann J, Weißmann M, Knoll A, Steindorf K, Sieverding M. Social support and social control in the context of cancer patients ' exercise: A pilot study. January, 2016.

24. Márcia S, Braido NF, Ottaviani AC, Gesualdo GD, Zazzetta MS. Social support of adults and elderly with chronic kidney disease on dialysis. 2016.

25. Adedimeji AA, Alawode 00, Odutolu O. Impact of Care and Social Support on Wellbeing among people living with Impact of Care and Social Support on Wellbeing among people living with HIV / AIDS in Nigeria. June, 2014.

\section{Figures}

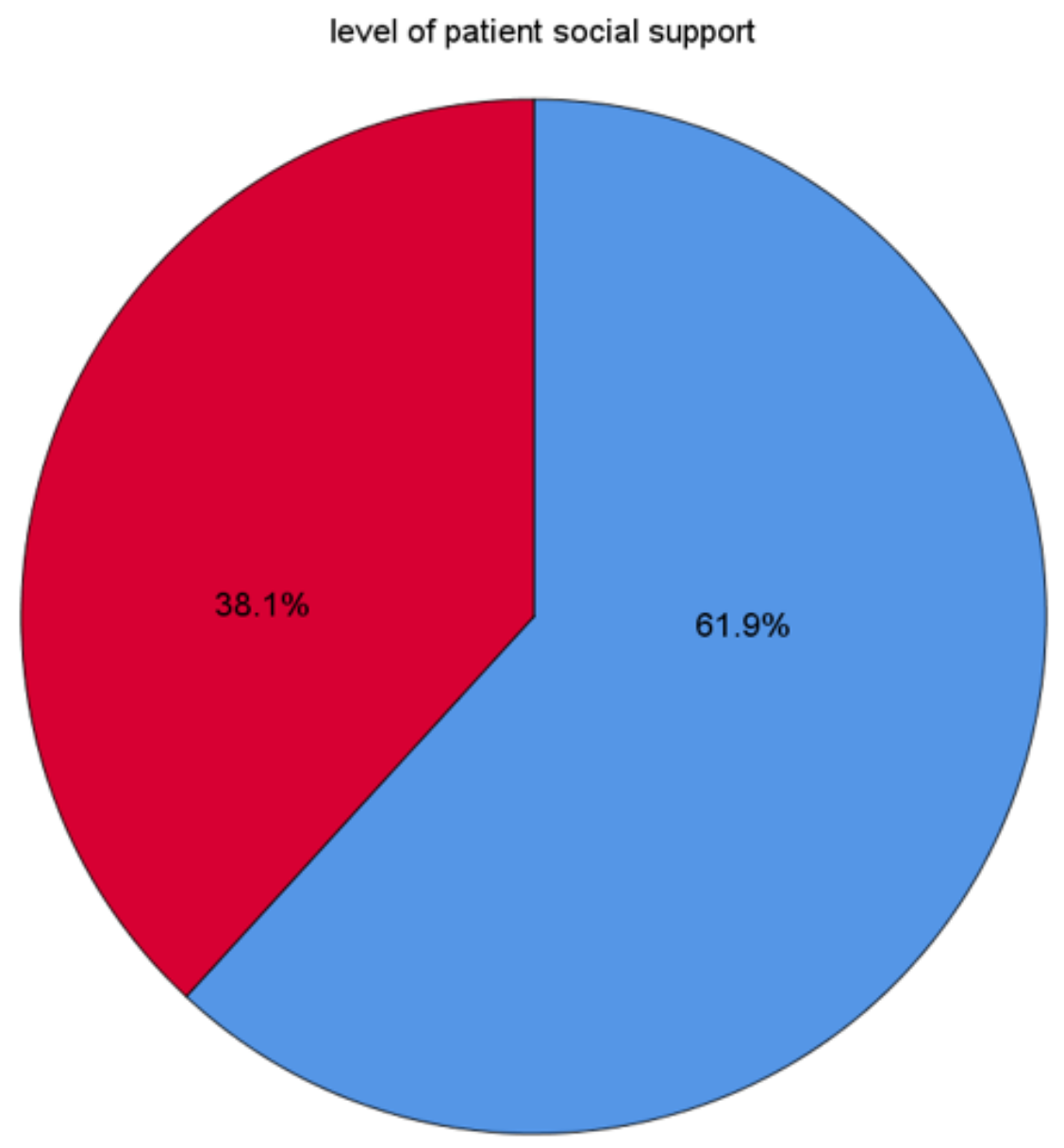

low social support

high social support 


\section{Figure 1}

Level of patient social support among hospitalized medical surgical inpatient in public hospital, Addis Ababa, Ethiopia, 2020 ( $n=380)$. 